\title{
Comparison of colorectal cancer screening between people with and without disability: a nationwide matched cohort study
}

Chun-Ming Liao ${ }^{1,2+}$, Wen-Hao Huang ${ }^{3+}$, Pei-Tseng Kung ${ }^{4,5^{*}+}$, Li-Ting Chiu ${ }^{6}$ and Wen-Chen Tsai ${ }^{6 *+}$

\begin{abstract}
Background: The World Health Organization has recognized that people with disability are among the most marginalized in the world. This study's objective was to investigate the differences in the probability of colorectal cancer (CRC) screening with faecal immunochemical testing (FIT) between people with disability and without disability in Taiwan.
\end{abstract}

Methods: The study participants included people with and without disability from the Disability Registration Database (2012) and the National Health Insurance Research Database (2009-2012). The study included 50- to 69-year-olds with and without disability who were screened from 2011 to 2012 and were alive in 2012. There were 16 categories of disability. After propensity score matching (PSM) between the two groups, conditional logistic regression analysis with control variables was used to investigate the odds ratio (OR) that people with or without disability would undergo CRC screening.

Results: The percentage of people with disability receiving CRC screening was $21.84 \%$, and the highest rate of those receiving CRC screening (38.72\%) was found in people with intractable epilepsy, whose OR was 1.47 times that of people with moving functional limitation ( $95 \%$ confidence interval $(\mathrm{Cl})=1.17-1.85$ ). The results showed that the probability of CRC screening in people with disability was lower than that in people without disability $(\mathrm{OR}=0.88$, $95 \% \mathrm{Cl}=0.87-0.89$ ). The probability of receiving CRC screening differed between people with different categories of disability.

Conclusions: Although the probability of CRC screening in the four categories of disability was higher than that in the general population, overall, people with disability were less likely than people without disability to undergo CRC screening. Health inequalities still exist under National Health Insurance in Taiwan.

Keywords: Disability, Colorectal cancer, Colorectal cancer screening

\footnotetext{
* Correspondence: ptkung@asia.edu.tw; wctsai2011@gmail.com

${ }^{+}$Chun-Ming Liao and Wen-Hao Huang contributed equally to this work as the first author. Pei-Tseng Kung and Wen-Chen Tsai contributed equally to this work as the corresponding author

${ }^{4}$ Department of Healthcare Administration, Asia University, Taichung, Taiwan

${ }^{6}$ Department of Health Services Administration, China Medical University, No.

100, Sec. 1, Jingmao Road, Beitun District, Taichung 406040, Taiwan

Full list of author information is available at the end of the article
}

(c) The Author(s). 2021 Open Access This article is licensed under a Creative Commons Attribution 4.0 International License, which permits use, sharing, adaptation, distribution and reproduction in any medium or format, as long as you give appropriate credit to the original author(s) and the source, provide a link to the Creative Commons licence, and indicate if changes were made. The images or other third party material in this article are included in the article's Creative Commons licence, unless indicated otherwise in a credit line to the material. If material is not included in the article's Creative Commons licence and your intended use is not permitted by statutory regulation or exceeds the permitted use, you will need to obtain permission directly from the copyright holder. To view a copy of this licence, visit http://creativecommons.org/licenses/by/4.0/ The Creative Commons Public Domain Dedication waiver (http://creativecommons.org/publicdomain/zero/1.0/) applies to the data made available in this article, unless otherwise stated in a credit line to the data. 


\section{Background}

A World Health Organization (WHO) survey in 2010 showed that the number of people with disability exceeds one billion globally (approximately 15.6-19.4\% of the global population) and has been increasing in recent years [1]. The WHO report also noted that people with disability are one of the most marginalized groups in the world, and they generally suffer from poor health, difficulty accessing education, and low socioeconomic status, though these inequities often can be overcome through active effort [2]. The WHO has found that people with disability are twice as likely as the general population (without disability) to be denied access to health care and up to three times as likely to suffer from inappropriate medical treatment [2]. In Taiwan, the number of people with disability reached 1.17 million in 2014 (approximately $5 \%$ of the population), and due to the ageing of the population, this number has been increasing significantly over the years [3].

In the past decade, cancer has been the leading cause of death in Taiwan, and colorectal cancer (CRC) has the highest incidence among all cancers. Therefore, since 2004, Taiwan's Ministry of Health and Welfare has been promoting free faecal immunochemical testing (FIT) for $\mathrm{CRC}$ and other cancer screenings for people aged 50 to 69 years (after June 1, 2013, the age range was changed to 50-74 years), and the screening rate within 2 years has risen to approximately $40 \%$ in recent years [3]. A metaanalysis showed that people with disability are not significantly less likely to undergo FIT than people without disability [4]. Another study using public data from the National Health Interview Survey also showed that people with disability were less likely to undergo CRC screening in 1998, but there was no difference in 2010 [5]. In contrast to the above viewpoints, one systematic review in 2020 screened more than 5000 articles and, after analysing 18 of them, concluded that although people with disability share many of the same barriers as people without disability, their utilization rate of cancer treatment is not higher than that of people without disability but their utilization rate of cancer screening is much lower [6]. In Taiwan, where free health checks have been available to adults for more than a decade, several studies have shown that people with disability are significantly less likely to receive free health checks than others [7-9]. The probability of cervical cancer screening in people with disability is lower than that in people without disability [10-12]. The probability of breast cancer screening in people with disability is also lower than that in people without disability, especially for women with mental disorders [13]. Few international articles have compared CRC screening between people with and without disability, and the conclusions are not consistent. In Taiwan, there are no articles on CRC screening among people with disability.
A large US study ( $>4$ million subjects) showed that the probability of CRC screening (83.1\%) in the 51-75year-old age group reached the target of $\geq 80 \%$, contributing to a significant reduction in the mortality risk of CRC $[14,15]$. In fact, the probability of CRC screening varies widely among different ethnic groups, and inconsistent screening rates have caused difficulties in the implementation of public health policies [16]. Although the screening rate (once every two years) for CRC in Taiwan is approximately $40 \%$ [3], a time series analysis taking Taiwanese people as the sample showed that over the years, due to the implementation of National Health Insurance (NHI) and medical technology advances in Taiwan, a significant reduction in the mortality rate of CRC has been achieved [17]. Other studies using different statistical methods to determine the CRC screening rate have also drawn the same conclusion; that is, the death risk of CRC decreases year by year $[18,19]$. Furthermore, increasing the screening rate allows early treatment in patients and a better survival rate, a conclusion drawn by many cancer-related studies [20-22].

The objective of this study was to investigate the differences in the probability of CRC screening between people with and without disability in Taiwan.

\section{Methods}

\section{Data sources}

In this study, the Disability Registration Database (2012) of the Ministry of the Interior of Taiwan and the $\mathrm{Na}$ tional Health Insurance Research Database (NHIRD) (2009-2012) provided by the Ministry of Health and Welfare of Taiwan were used as the population source and were combined with national catastrophic illness/injury data as of December 2012. The total number of people under Taiwan's NHI was 23.621 million [23], and the coverage rate was $99.9 \%$ [24]. The data from this study are representative of the Taiwanese population.

The Disability Registration Database in Taiwan is established and maintained by the Ministry of the Interior of Taiwan. Under Taiwan's Physically and Mentally Disabled Citizens Protection Act, after assessment by a governmentcertified professional physician, people with disability must apply to the Department of Social Welfare of a county or city, obtain a permit, and notify the Ministry of the Interior of Taiwan to complete the registration.

Patient identifications in the NHIRD and the Disability Registration Database were scrambled to ensure privacy. All patients without identifications for public use and personal privacy were protected in this study. The study guidelines followed for this study were in accordance with the Declaration of Helsinki. The Research Ethics Committee of Dali JEN-AI Hospital waived the informed consent in this study and approved this study (IRB No: 105-14). 


\section{Participants}

According to Taiwan's Physically and Mentally Disabled Citizens Protection Act, this study classified 16 categories of disability (moving functional limitation, internal organ function loss and related disabilities, hearing impairment, multiple disabilities, chronic mental health conditions, visual impairment, intellectual and developmental disability, dementia, vocal and speech impairment, motion and balance impairment, facial disfigurements, intractable epilepsy, rare diseases, autism, persistent vegetative state, and other (chromosomal abnormalities, inborn errors of metabolism, and birth defects)) and four severity levels of disability (mild, moderate, severe, and profound). People in a persistent vegetative state (PVS) are not suitable for the purpose of this study, so this category was excluded.

The objective of this study was to calculate the differences in the probability of CRC screening (FIT) between people with and without disability. Among the people aged 50-69 years who received a free screening under NHI between 2011 and 2012, there were 345,811 people with disability and 4,763,347 people without disability. Among those with disability, 2250 people who had already entered a PVS and 44,454 people who were diagnosed with cancer before 2011 were excluded. Among the people without disability, 313,009 people who had cancer before 2011 were excluded. Finally, 299,107 people with disability and 4,450,338 people without disability were included in this study (Fig. 1).

\section{Variable descriptions and definitions}

Because free CRC screening with FIT in Taiwan is conducted once every 2 years for eligible people [3], the dependent variable was whether the study participants received CRC screening in 2011 or 2012. The independent variables were category of disability (15 types), severity of disability (four levels), and whether one did or did not have a disability (i.e., covering those with or without disability who met the CRC screening criteria), and the control variables were sex (male or female), age (50-59 or 60-69 years), and socioeconomic status (monthly salary, including low income, $\leq 17,280$ NT\$, 17,281-22,800 NT\$, 22,801-28,800 NT\$, 28,801-36,300 NT\$, and $\geq 36$, 301 NT\$). The environmental factor was represented by the urbanization level of the residential area. Based on a 2006 study by Liu et al. [25], the 359 townships in Taiwan were classified into seven levels. Townships with the highest urbanization level were classified as the first level, and those with the lowest urbanization level were classified as the seventh level [25]. Health condition was measured by the comorbidity severity of each subject. According to the Charlson comorbidity index (CCI) modified by Deyo et al. [26], the ICD-9-CM primary and secondary codes of each subject were converted into numerical weight scores to represent the comorbidity severity, which included $0,1,2$, and $\geq 3$ points in this study; the higher the score, the more severe the comorbidity is. The preventive health care behaviour of the study participants was represented by their participation in free dental cleaning and the use of free adult health examinations under NHI. Taiwan National Health Insurance offers free preventive dental calculus cleaning once every 6 months for all people. Thus, the receipt of dental calculus cleaning in 2011-2012 was used as a variable. Taiwan's NHI also provides a free adult health examination once every 3 years for people aged between 40 and

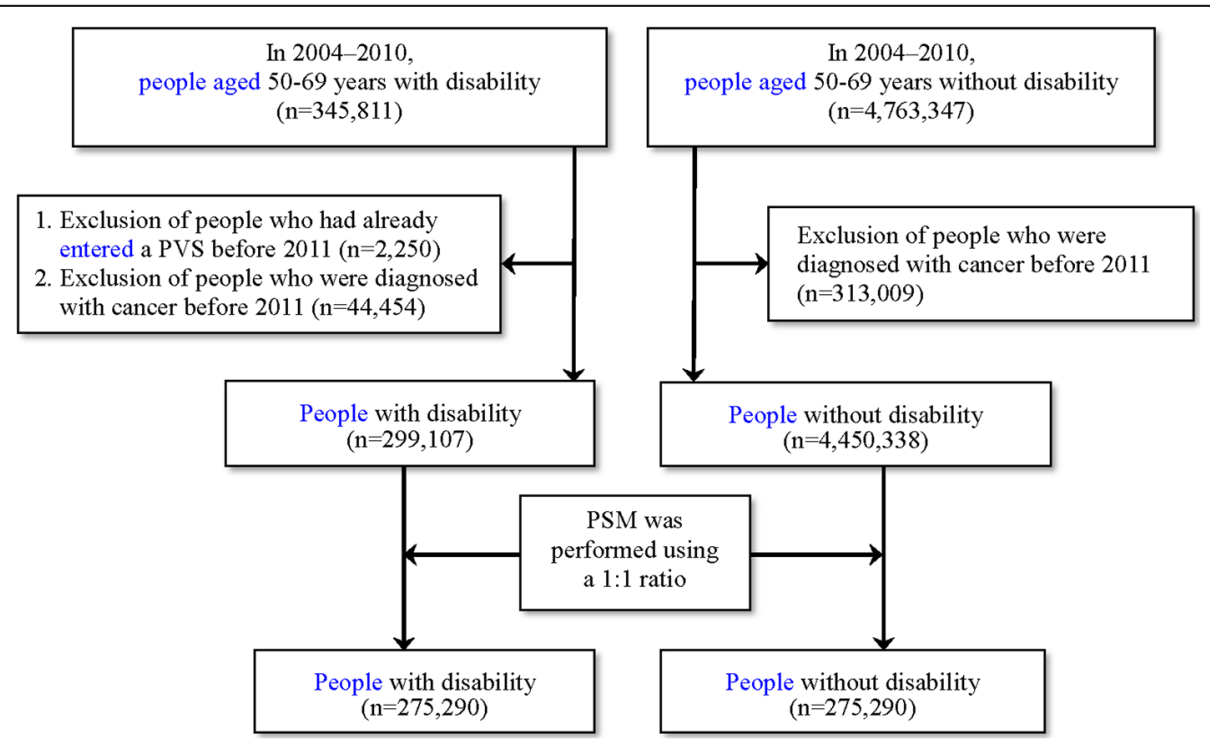

Fig. 1 Process of selecting the study participants meeting the CRC screening criteria 
65 years and once every year for people aged 65 years and above. The receipt of a free adult health examination under NHI in 2011-2012 was used as the second variable.

\section{Analytical methods}

This study was a retrospective cohort study. SAS 9.4 (SAS Institute Inc., Cary, NC) was used for statistical analysis.

First, the probability of receiving CRC screening for people with different categories of disability and different severity levels of disability was analysed, and the chisquared $\left(x^{2}\right)$ test was used to compare the probability of receiving CRC between two groups to determine whether there were significant differences in the distribution of people $(P<0.05)$. Then, the probability of receiving CRC screening was analysed by conditional logistic regression after adding the control variables (seven variables) to investigate the odds ratio (OR) and factors relevant to CRC screening in people with different categories of disability and different severity levels of disability.

To calculate the differences in the probability of CRC screening between people with and without disability who met the screening criteria, since people with disability (observation group) and people without disability (control group) were not randomly enrolled, propensity score matching (PSM) was used to reduce the selection bias between the two groups [27]. First, we built a multivariate logistic regression model with relevant factors, including demographic characteristics, socioeconomic status, environmental factors, and health conditions, to calculate the predicted probability for people with disability. We then used the closest propensity score to match the people with and without disability at a ratio of 1:1 to generate the observation and control groups. If a person with disability (observation group) could not be matched with any person without disability (control group) via the greedy algorithm, then this person was excluded from the observation group. A chi-squared $\left(x^{2}\right)$ test was performed to test the people with disability (observation group) and people without disability (control group) to confirm that the distribution of people for each variable was not significantly different between the two groups $(P>0.05)$. Furthermore, before comparing the likelihood of undergoing CRC screening between people with and without disability, the observation and control groups were tested by the $x^{2}$ test to determine whether there was a significant difference in the distribution of each variable between the two groups $(P<0.05)$. Next, in Model A with the seven control variables, conditional logistic regression was used to analyse the probability of CRC screening in people with and without disability to investigate the $\mathrm{OR}$ and its influencing factors. Finally, in Model B, the people with disability were divided into 15 categories. After adding the control variables (seven variables), the OR and relevant factors of receiving CRC screening in the general population and people in the 15 categories of disability were investigated separately.

\section{Results}

Table 1 shows the comparison of the number of people with disability who did and did not undergo CRC screening, and the $x^{2}$ test was used to compare the two groups. The results showed that the number of people with disability who underwent CRC screening $(65,329$, $21.84 \%$ ) was lower than that of people with disability who did not receive CRC screening (233,778, 78.16\%). Among the categories of disability, the percentage of people receiving CRC screening was highest among people with intractable epilepsy (139 patients, 38.72\%) and lowest among people with dementia (450 patients, $11.86 \%)$. With the increase in severity level, the percentage of people receiving CRC screening tended to decrease, from $27.05 \%$ (mild) to $14.13 \%$ (profound). The percentage of people receiving $\mathrm{CRC}$ screening decreased as comorbidity severity increased, from $23.61 \%(\mathrm{CCI}=0)$ to $14.94 \%(\mathrm{CCI} \geq 3)$.

Table 2 shows the results of the logistic regression analysis. With the control variables considered, compared to the OR in people with moving functional limitation, the ORs of receiving CRC screening in people with intractable epilepsy ( $\mathrm{OR}=1.47$ (i.e., 47\% higher), 95\% confidence interval $(\mathrm{CI})=1.17-1.85)$, internal organ function loss and related disabilities $(\mathrm{OR}=1.34,95 \% \mathrm{CI}=1.29-1.39)$, chronic mental health conditions $(\mathrm{OR}=1.29,95 \% \mathrm{CI}=1.24-1.33)$, and hearing impairment $(\mathrm{OR}=1.22,95 \% \mathrm{CI}=1.18-1.26)$ were higher, while those of people with intellectual and developmental disability $(\mathrm{OR}=0.72,95 \% \mathrm{CI}=0.68-0.77)$ and dementia $(\mathrm{OR}=0.79,95 \% \mathrm{CI}=0.71-0.88)$ were lower. Compared to people with mild disability, the OR of receiving CRC screening decreased with the increase in the disability severity. The OR of receiving CRC screening in people with disability also decreased with the increase in the severity of comorbidities.

To understand the differences in the probability of CRC screening between people with and without disability, based on a rigorous study design, this study performed 1:1 PSM between people with and without disability. After matching, there were 275,290 participants in each group (Fig. 1). Testing showed no significant difference in the distribution of each variable between the two groups $(P>0.05)$ (Table 3$)$.

Table 4 shows the comparison of the uptake of CRC screening between people with and without disability after matching. The $x^{2}$ test was used to compare the observation group with the control group. After testing, 
Table 1 The Use of FIT for CRC Screening in People with Disability

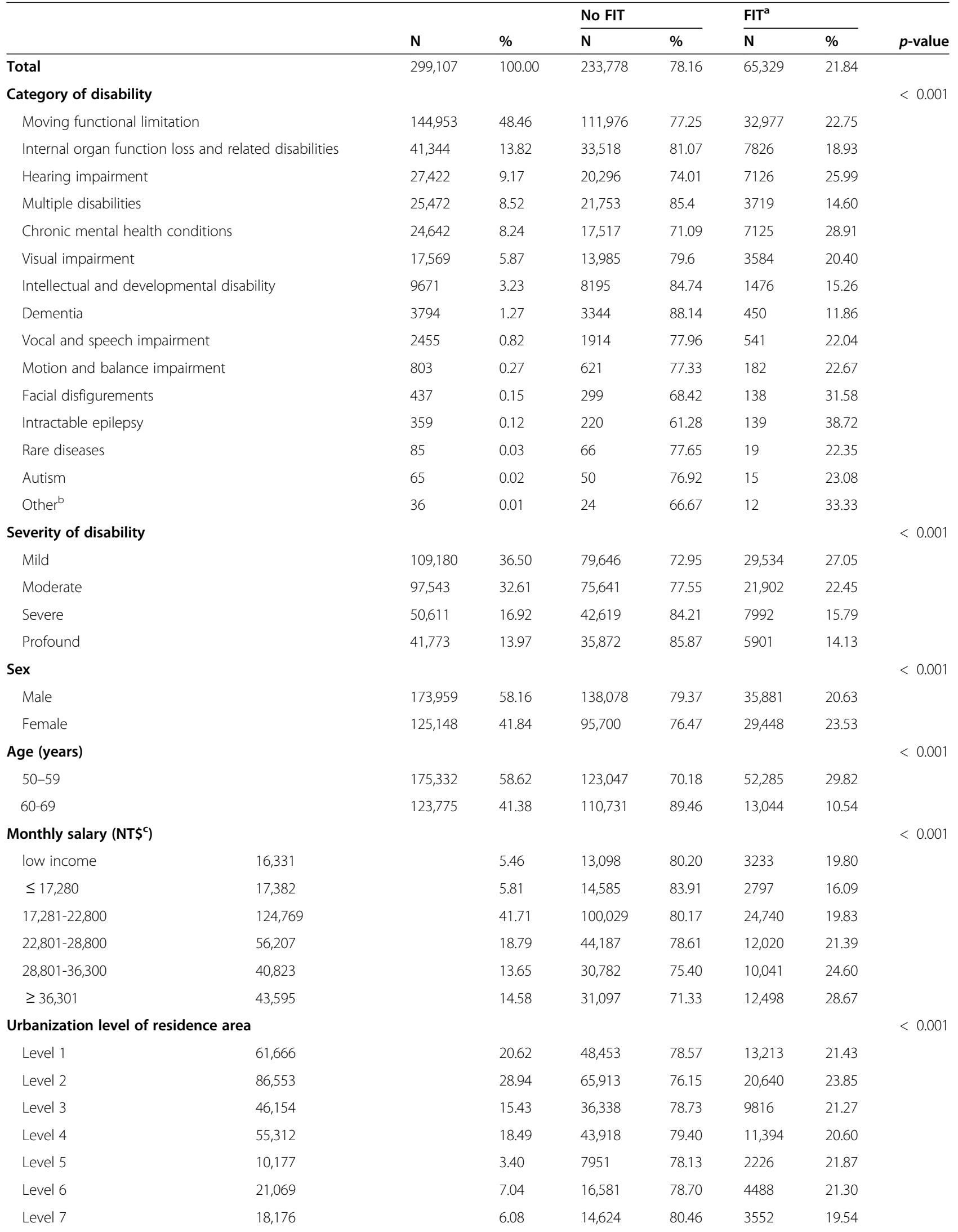


Table 1 The Use of FIT for CRC Screening in People with Disability (Continued)

\begin{tabular}{|c|c|c|c|c|c|c|c|c|}
\hline & & \multirow[b]{2}{*}{$\mathbf{N}$} & \multirow[b]{2}{*}{$\%$} & \multicolumn{2}{|l|}{ No FIT } & \multicolumn{2}{|l|}{$\mathrm{FIT}^{\mathrm{a}}$} & \multirow[b]{2}{*}{$p$-value } \\
\hline & & & & $\mathrm{N}$ & $\%$ & $\mathrm{~N}$ & $\%$ & \\
\hline $\mathrm{CCl}^{\mathrm{d}}$ & & & & & & & & $<0.001$ \\
\hline 0 & 131,068 & & 43.82 & 100,118 & 76.39 & 30,950 & 23.61 & \\
\hline 1 & 63,076 & & 21.09 & 47,143 & 74.74 & 15,933 & 25.26 & \\
\hline 2 & 42,825 & & 14.32 & 33,660 & 78.60 & 9165 & 21.40 & \\
\hline$\geq 3$ & 62,138 & & 20.77 & 52,857 & 85.06 & 9281 & 14.94 & \\
\hline Dental calculus cleaning & & & & & & & & $<0.001$ \\
\hline No & 227,891 & & 76.19 & 187,709 & 82.37 & 40,182 & 17.63 & \\
\hline Yes & 71,216 & & 23.81 & 46,069 & 64.69 & 25,147 & 35.31 & \\
\hline Adult health examination & & & & & & & & $<0.001$ \\
\hline No & 221,087 & & 73.92 & 184,436 & 83.42 & 36,651 & 16.58 & \\
\hline Yes & 78,020 & & 26.08 & 49,342 & 63.24 & 28,678 & 36.76 & \\
\hline
\end{tabular}

a. FIT faecal immunochemical testing; b. Other: chromosomal abnormalities, inborn errors of metabolism, congenital defects; c. NT\$ New Taiwan dollar; d. CCI Charlson comorbidity index.

the percentage of people with disability receiving CRC screening $(22.47 \%)$ was lower than that of people without disability $(27.18 \%)(P<0.05)$. The percentage of people in each category of disability receiving CRC screening was analysed, and the results showed that the highest percentage was found in people with intractable epilepsy (39.03\%), while the lowest was in people with dementia $(12.24 \%)$, which is similar to the results before matching. The number of people with disability was compared with that in the general population in terms of CRC screening. Among those with low income, the percentage of people with disability receiving CRC screening (20.97\%) was slightly higher than that of people without disability (19.45\%), but when distinguishing the subjects by all other variables, the percentage of people with disability receiving CRC screening was lower than that of people without disability. The subgroups with $\mathrm{CCI} \geq 3$ showed the largest difference $(-11.12 \%)$ in the rate of CRC screening uptake between people with disability (15.94\%) and without disability (27.06\%).

Table 5 shows the results of conditional logistic regression analysis with the control variables on the probability of CRC screening between people with and without disability (who met the CRC screening criteria). According to Model A, in general, the OR of undergoing CRC screening in people with disability was significantly lower than that in people without disability $(\mathrm{OR}=0.88,95 \% \mathrm{CI}=0.87$ $0.89)$. This $12 \%$ difference in the OR was statistically significant $(P<0.05)$. In Model $\mathrm{B}$, this study compared the differences in the OR of receiving CRC screening between the general population and people with different categories of disability. After controlling for different variables, the OR of receiving CRC screening in the four categories of disability (intellectual and developmental disability, dementia, multiple disabilities, moving functional limitation, and internal organ function loss and related disabilities) was significantly lower than that in the general population $(\mathrm{OR}=0.53,0.55,0.62,0.81,0.83)$, while the $\mathrm{OR}$ in the other four categories of disability (chronic mental health conditions, visual impairment, and intractable epilepsy) was significantly higher than that in the general population $(\mathrm{OR}=1.04,1.09,1.53$, respectively). The probability of receiving CRC screening in people with different categories of disability was different from that of the general population, and the differences were statistically significant $(P<0.05)$.

\section{Discussion}

Under Taiwan's NHI system, among the people with disability who are eligible for free CRC screening, only $21.84 \%$ were screened. This study also found significant differences in the probability of CRC screening among people with different categories of disability who were eligible for free CRC screening. For example, the probability of receiving CRC screening in people with cognitive disability and dementia $(\mathrm{OR}=0.72,0.79)$ was significantly lower than that in people with mobility disability, while the probability of receiving CRC screening in people with mobility disability was significantly lower than that in people with intractable epilepsy, internal organ function loss and related disabilities, chronic mental health conditions, and hearing impairment $(\mathrm{OR}=$ $1.47,1.34,1.29$, and 1.22 , respectively), similar to the results for cervical cancer screening in Taiwan [12]. This study suggests that Taiwan should establish environments and services providing free CRC screening that are more tailored toward people with cognitive and mobility disabilities in the future.

This study found that under Taiwan's NHI system, among people meeting the free CRC screening criteria, 
Table 2 Factors Associated with the Use of FIT for CRC Screening in People with Disability

\begin{tabular}{|c|c|c|c|c|}
\hline & OR & $95 \% \mathrm{Cl}$ & & $p$-value \\
\hline \multicolumn{5}{|l|}{ Category of disability } \\
\hline Moving functional limitation (ref) & 1.00 & - & - & - \\
\hline Internal organ function loss and related disabilities & 1.34 & 1.29 & 1.39 & $<0.001$ \\
\hline Hearing impairment & 1.22 & 1.18 & 1.26 & $<0.001$ \\
\hline Multiple disabilities & 1.00 & 0.96 & 1.05 & 0.885 \\
\hline Chronic mental health conditions & 1.29 & 1.24 & 1.33 & $<0.001$ \\
\hline Visual impairment & 1.03 & 0.99 & 1.07 & 0.197 \\
\hline Intellectual and developmental disability & 0.72 & 0.68 & 0.77 & $<0.001$ \\
\hline Dementia & 0.79 & 0.71 & 0.88 & $<0.001$ \\
\hline Vocal and speech impairment & 1.08 & 0.97 & 1.20 & 0.152 \\
\hline Motion and balance impairment & 1.14 & 0.95 & 1.36 & 0.163 \\
\hline Facial disfigurements & 1.17 & 0.94 & 1.45 & 0.166 \\
\hline Intractable epilepsy & 1.47 & 1.17 & 1.85 & 0.001 \\
\hline Rare diseases & 0.92 & 0.53 & 1.61 & 0.771 \\
\hline Autism & 0.89 & 0.48 & 1.65 & 0.716 \\
\hline Other ${ }^{a}$ & 1.77 & 0.85 & 3.69 & 0.129 \\
\hline \multicolumn{5}{|l|}{ Sex } \\
\hline Male (ref) & 1.00 & - & - & - \\
\hline Female & 1.19 & 1.16 & 1.21 & $<0.001$ \\
\hline \multicolumn{5}{|l|}{ Age (years) } \\
\hline 50-59 (ref) & 1.00 & - & - & - \\
\hline $60-69$ & 0.23 & 0.22 & 0.23 & $<0.001$ \\
\hline \multicolumn{5}{|l|}{ Monthly salary (NT\$ ${ }^{\mathrm{b}}$ ) } \\
\hline Low income (ref) & 1.00 & - & - & - \\
\hline$\leq 17,280$ & 0.89 & 0.83 & 0.94 & $<0.001$ \\
\hline $17,281-22,800$ & 1.07 & 1.02 & 1.12 & 0.007 \\
\hline $22,801-28,800$ & 1.05 & 1.00 & 1.10 & 0.048 \\
\hline $28,801-36,300$ & 1.17 & 1.11 & 1.23 & $<0.001$ \\
\hline$\geq 36,301$ & 1.40 & 1.33 & 1.47 & $<0.001$ \\
\hline \multicolumn{5}{|l|}{ Urbanization level of residence area } \\
\hline 1 (ref) & 1.00 & - & - & - \\
\hline 2 & 1.14 & 1.11 & 1.17 & $<0.001$ \\
\hline 3 & 1.04 & 1.01 & 1.08 & 0.010 \\
\hline 4 & 1.07 & 1.03 & 1.10 & $<0.001$ \\
\hline 5 & 1.34 & 1.26 & 1.42 & $<0.001$ \\
\hline 6 & 1.21 & 1.16 & 1.27 & $<0.001$ \\
\hline 7 & 1.13 & 1.08 & 1.18 & $<0.001$ \\
\hline \multicolumn{5}{|l|}{$\mathrm{CCl}^{\mathrm{c}}$} \\
\hline 0 (ref) & 1.00 & - & - & - \\
\hline 1 & 1.24 & 1.21 & 1.27 & $<0.001$ \\
\hline 2 & 1.22 & 1.19 & 1.26 & $<0.001$ \\
\hline$\geq 3$ & 1.04 & 1.00 & 1.07 & 0.027 \\
\hline
\end{tabular}

Severity of disability 
Table 2 Factors Associated with the Use of FIT for CRC Screening in People with Disability (Continued)

\begin{tabular}{|c|c|c|c|c|}
\hline \multirow{2}{*}{ Moderate } & \multirow{2}{*}{$\frac{\text { OR }}{0.85}$} & \multicolumn{2}{|c|}{$95 \% \mathrm{Cl}$} & \multirow{2}{*}{$\frac{p \text {-value }}{<0.001}$} \\
\hline & & 0.84 & 0.87 & \\
\hline Severe & 0.62 & 0.60 & 0.64 & $<0.001$ \\
\hline Profound & 0.56 & 0.54 & 0.59 & $<0.001$ \\
\hline \multicolumn{5}{|c|}{ Dental calculus cleaning } \\
\hline No (ref) & 1.00 & - & - & - \\
\hline Yes & 1.88 & 1.84 & 1.92 & $<0.001$ \\
\hline \multicolumn{5}{|c|}{ Adult health examination } \\
\hline No (ref) & 1.00 & - & - & - \\
\hline Yes & 3.32 & 3.25 & 3.39 & $<0.001$ \\
\hline
\end{tabular}

a. Others: chromosomal abnormalities, inborn errors of metabolism, and congenital defects; b. NT\$ New Taiwan dollar; c. CCI Charlson comorbidity index.

Table 3 Distribution after Matching between People with and without Disability

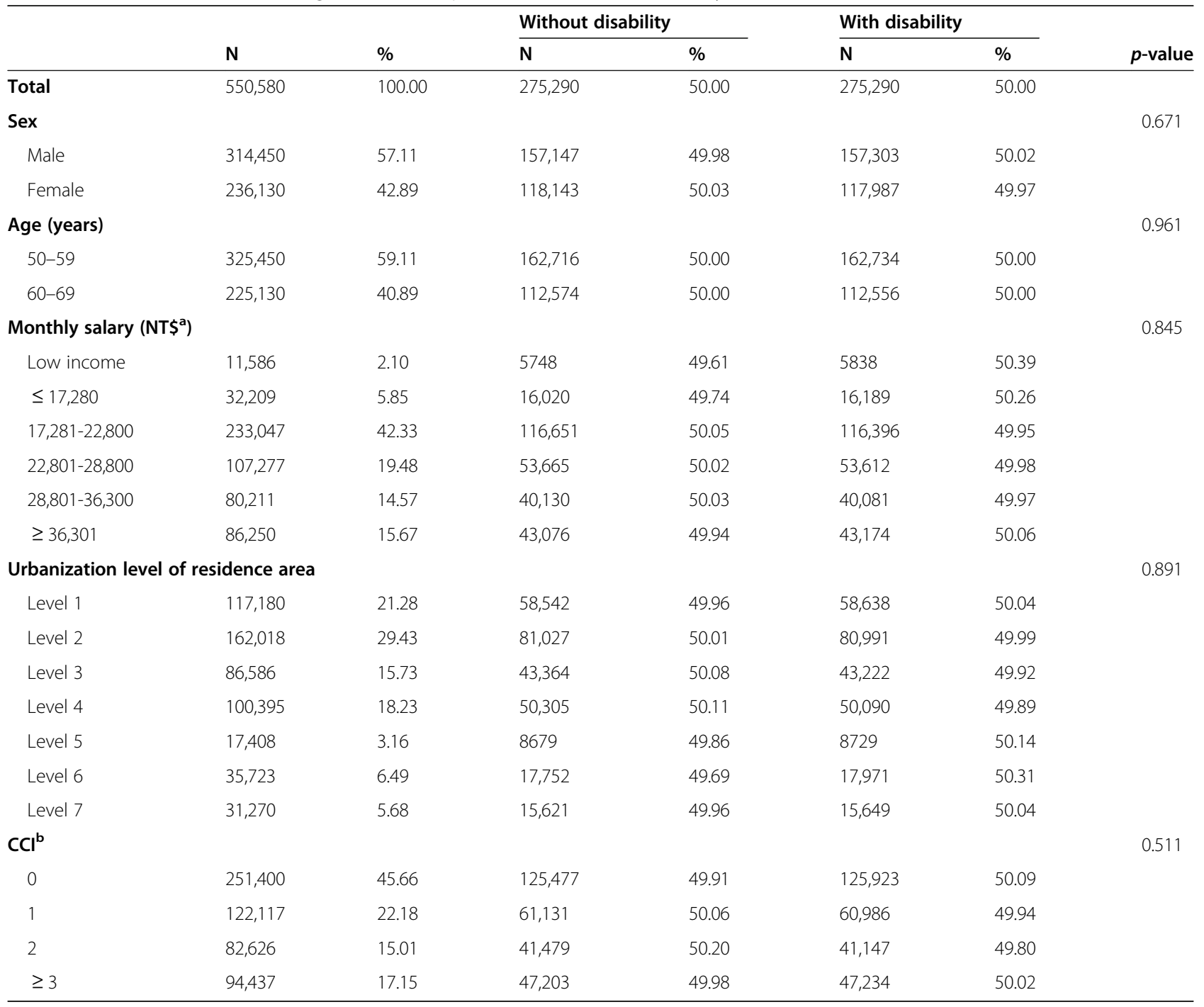

a. NT\$ New Taiwan dollar; b. CCl Charlson comorbidity index. 
Table 4 Comparison of the Use of FIT for CRC Screening between People with and without Disability after Matching

\begin{tabular}{|c|c|c|c|c|c|c|c|c|c|c|c|}
\hline & \multirow[b]{3}{*}{$\mathbf{N}$} & \multirow[b]{3}{*}{$\%$} & \multicolumn{4}{|c|}{ Without disability $(N=275,290)$} & \multicolumn{4}{|c|}{ With disability $(N=275,290)$} & \multirow[b]{3}{*}{$p$-value } \\
\hline & & & \multirow{2}{*}{$\begin{array}{l}\text { No FIT } \\
\mathrm{N}\end{array}$} & \multicolumn{3}{|l|}{$\mathrm{FIT}^{\mathrm{a}}$} & \multicolumn{2}{|l|}{ No FIT } & \multicolumn{2}{|l|}{ FIT } & \\
\hline & & & & $\%$ & $\mathbf{N}$ & $\%$ & $\mathbf{N}$ & $\%$ & $\mathbf{N}$ & $\%$ & \\
\hline Total & 550,580 & 100.00 & 200,478 & 72.82 & 74,812 & 27.18 & 213,438 & 77.53 & 61,852 & 22.47 & $<0.001$ \\
\hline \multicolumn{12}{|l|}{ Sex } \\
\hline Male & 314,450 & 57.11 & 117,974 & 75.07 & 39,173 & 24.93 & 123,868 & 78.74 & 33,435 & 21.26 & $<0.001$ \\
\hline Female & 236,130 & 42.89 & 82,504 & 69.83 & 35,639 & 30.17 & 89,570 & 75.92 & 28,417 & 24.08 & $<0.001$ \\
\hline \multicolumn{12}{|l|}{ Age (years) } \\
\hline $50-59$ & 325,450 & 59.11 & 105,844 & 65.05 & 56,872 & 34.95 & 113,333 & 69.64 & 49,401 & 30.36 & $<0.001$ \\
\hline $60-69$ & 225,130 & 40.89 & 94,634 & 84.06 & 17,940 & 15.94 & 100,105 & 88.94 & 12,451 & 11.06 & $<0.001$ \\
\hline \multicolumn{12}{|l|}{ Monthly salary (NT\$ $\$^{\mathrm{b}}$ ) } \\
\hline Low income & 11,586 & 2.10 & 4630 & 80.55 & 1118 & 19.45 & 4614 & 79.03 & 1224 & 20.97 & 0.045 \\
\hline$\leq 17,280$ & 32,209 & 5.85 & 11,984 & 74.81 & 4036 & 25.19 & 13,486 & 83.30 & 2703 & 16.70 & $<0.001$ \\
\hline $17,281-22,800$ & 233,047 & 42.33 & 86,836 & 74.44 & 29,815 & 25.56 & 92,579 & 79.54 & 23,817 & 20.46 & $<0.001$ \\
\hline $22,801-28,800$ & 107,277 & 19.48 & 39,300 & 73.23 & 14,365 & 26.77 & 41,872 & 78.10 & 11,740 & 21.90 & $<0.001$ \\
\hline $28,801-36,300$ & 80,211 & 14.57 & 28,509 & 71.04 & 11,621 & 28.96 & 30,176 & 75.29 & 9905 & 24.71 & $<0.001$ \\
\hline$\geq 36,301$ & 86,250 & 15.67 & 29,219 & 67.83 & 13,857 & 32.17 & 30,711 & 71.13 & 12,463 & 28.87 & $<0.001$ \\
\hline \multicolumn{12}{|l|}{ Urbanization level of residence area } \\
\hline Level 1 & 117,180 & 21.28 & 43,212 & 73.81 & 15,330 & 26.19 & 45,845 & 78.18 & 12,793 & 21.82 & $<0.001$ \\
\hline Level 2 & 162,018 & 29.43 & 58,012 & 71.60 & 23,015 & 28.40 & 61,078 & 75.41 & 19,913 & 24.59 & $<0.001$ \\
\hline Level 3 & 86,586 & 15.73 & 31,725 & 73.16 & 11,639 & 26.84 & 33,883 & 78.39 & 9339 & 21.61 & $<0.001$ \\
\hline Level 4 & 100,395 & 18.23 & 37,010 & 73.57 & 13,295 & 26.43 & 39,444 & 78.75 & 10,646 & 21.25 & $<0.001$ \\
\hline Level 5 & 17,408 & 3.16 & 6304 & 72.64 & 2375 & 27.36 & 6716 & 76.94 & 2013 & 23.06 & $<0.001$ \\
\hline Level 6 & 35,723 & 6.49 & 12,884 & 72.58 & 4868 & 27.42 & 14,057 & 78.22 & 3914 & 21.78 & $<0.001$ \\
\hline Level 7 & 31,270 & 5.68 & 11,331 & 72.54 & 4290 & 27.46 & 12,415 & 79.33 & 3234 & 20.67 & $<0.001$ \\
\hline \multicolumn{12}{|l|}{$\mathrm{CCl}^{\mathrm{C}}$} \\
\hline 0 & 251,400 & 45.66 & 93,789 & 74.75 & 31,688 & 25.25 & 95,965 & 76.21 & 29,958 & 23.79 & $<0.001$ \\
\hline 1 & 122,117 & 22.18 & 43,133 & 70.56 & 17,998 & 29.44 & 45,505 & 74.62 & 15,481 & 25.38 & $<0.001$ \\
\hline 2 & 82,626 & 15.01 & 29,125 & 70.22 & 12,354 & 29.78 & 32,262 & 78.41 & 8885 & 21.59 & $<0.001$ \\
\hline$\geq 3$ & 94,437 & 17.15 & 34,431 & 72.94 & 12,772 & 27.06 & 39,706 & 84.06 & 7528 & 15.94 & $<0.001$ \\
\hline \multicolumn{12}{|l|}{ Dental calculus cleaning } \\
\hline No & 382,333 & 69.44 & 135,329 & 77.28 & 39,797 & 22.72 & 169,483 & 81.79 & 37,724 & 18.21 & $<0.001$ \\
\hline Yes & 168,247 & 30.56 & 65,149 & 65.04 & 35,015 & 34.96 & 43,955 & 64.56 & 24,128 & 35.44 & 0.043 \\
\hline \multicolumn{12}{|l|}{ Adult health examination } \\
\hline No & 379,637 & 68.95 & 140,250 & 78.95 & 37,383 & 21.05 & 167,375 & 82.86 & 34,629 & 17.14 & $<0.001$ \\
\hline Yes & 170,943 & 31.05 & 60,228 & 61.67 & 37,429 & 38.33 & 46,063 & 62.85 & 27,223 & 37.15 & $<0.001$ \\
\hline \multicolumn{12}{|l|}{ Category of disability } \\
\hline Moving Functional Limitation & 135,434 & 24.60 & & & & & 103,801 & 76.64 & 31,633 & 23.36 & \\
\hline Internal organ function loss and related disabilities & 36,775 & 6.68 & & & & & 29,423 & 80.01 & 7352 & 19.99 & \\
\hline Hearing impairment & 26,716 & 4.85 & & & & & 19,700 & 73.74 & 7016 & 26.26 & \\
\hline Multiple disabilities & 21,919 & 3.98 & & & & & 18,602 & 84.87 & 3317 & 15.13 & \\
\hline Chronic mental health conditions & 22,128 & 4.02 & & & & & 15,740 & 71.13 & 6388 & 28.87 & \\
\hline Visual impairment & 16,430 & 2.98 & & & & & 12,981 & 79.01 & 3449 & 20.99 & \\
\hline Intellectual and developmental disability & 8326 & 1.51 & & & & & 7070 & 84.91 & 1256 & 15.09 & \\
\hline Dementia & 3521 & 0.64 & & & & & 3090 & 87.76 & 431 & 12.24 & \\
\hline
\end{tabular}


Table 4 Comparison of the Use of FIT for CRC Screening between People with and without Disability after Matching (Continued)

\begin{tabular}{|c|c|c|c|c|c|c|c|c|c|c|c|}
\hline & \multirow[b]{3}{*}{$\mathbf{N}$} & \multirow[b]{3}{*}{$\%$} & \multicolumn{4}{|c|}{ Without disability $(N=275,290)$} & \multicolumn{4}{|c|}{ With disability $(N=275,290)$} & \multirow[b]{3}{*}{$p$-value } \\
\hline & & & \multirow{2}{*}{$\begin{array}{l}\text { No FIT } \\
\mathrm{N}\end{array}$} & \multicolumn{3}{|c|}{$\mathrm{FIT}^{\mathrm{a}}$} & \multicolumn{2}{|c|}{ No FIT } & \multicolumn{2}{|l|}{ FIT } & \\
\hline & & & & $\%$ & $\mathbf{N}$ & $\%$ & $\mathrm{~N}$ & $\%$ & $\mathrm{~N}$ & $\%$ & \\
\hline Vocal and speech impairment & 2318 & 0.42 & & & & & 1802 & 77.74 & 516 & 22.26 & \\
\hline Motion and balance impairment & 770 & 0.14 & & & & & 596 & 77.40 & 174 & 22.60 & \\
\hline Facial disfigurements & 426 & 0.08 & & & & & 289 & 67.84 & 137 & 32.16 & \\
\hline Intractable epilepsy & 351 & 0.06 & & & & & 214 & 60.97 & 137 & 39.03 & \\
\hline Rare diseases & 85 & 0.02 & & & & & 66 & 77.65 & 19 & 22.35 & \\
\hline Autism & 57 & 0.01 & & & & & 42 & 73.68 & 15 & 26.32 & \\
\hline Others $^{\mathrm{d}}$ & 34 & 0.01 & & & & & 22 & 64.71 & 12 & 35.29 & \\
\hline
\end{tabular}

a. FIT faecal immunochemical testing; b. NT\$ New Taiwan dollar; c. CCI Charlson comorbidity index; d. Others: chromosomal abnormalities, inborn errors of metabolism, and congenital defects.

people with disability were less likely than people without disability to avail themselves of the free screening $(\mathrm{OR}=0.88)$. This empirical study clearly demonstrates that people with disability experience health inequality, as reported by the WHO, but this health inequality can be improved by various policies [2]. The results of this study showed that in Taiwan, in contrast to the conclusion reached by the WHO, people with disability are not twice as likely to be denied access to health care as people without disability [2]. In another difference from the data in the WHO report, this study showed that Taiwan has already significantly increased the probability of receiving CRC screening among people with disability, though there is still room for improvement. In contrast to the results of this study, a meta-analysis including two studies showed that the probability of CRC screening in people with disability was not significantly lower than that in people without disability. Of the studies collected

Table 5 Factors Associated with the Use of FIT for CRC Screening in People with and without Disability

\begin{tabular}{|c|c|c|c|c|c|c|c|c|}
\hline \multirow[b]{3}{*}{ Disability } & \multicolumn{4}{|c|}{ Model $A^{a}$} & \multicolumn{4}{|c|}{ Model Ba } \\
\hline & \multirow[t]{2}{*}{$\overline{\mathrm{OR}}$} & \multicolumn{2}{|c|}{$95 \% \mathrm{Cl}$} & \multirow[t]{2}{*}{$p$-value } & \multirow[t]{2}{*}{$\overline{O R}$} & \multicolumn{2}{|c|}{$95 \% \mathrm{Cl}$} & \multirow[t]{2}{*}{$p$-value } \\
\hline & & & & & & & & \\
\hline Without (ref) & 1.00 & - & - & - & & & & \\
\hline With & 0.88 & 0.87 & 0.89 & $<0.001$ & & & & \\
\hline \multicolumn{9}{|l|}{ Category of disability } \\
\hline Without disability (ref) & & & & & 1.00 & - & - & - \\
\hline Moving functional limitation & & & & & 0.81 & 0.77 & 0.84 & $<0.001$ \\
\hline Internal organ function loss and related disabilities & & & & & 0.83 & 0.81 & 0.86 & $<0.001$ \\
\hline Hearing impairment & & & & & 0.94 & 0.83 & 1.06 & 0.279 \\
\hline Multiple disabilities & & & & & 0.62 & 0.59 & 0.65 & $<0.001$ \\
\hline Chronic mental health conditions & & & & & 1.04 & 1.01 & 1.08 & 0.035 \\
\hline Visual impairment & & & & & 1.09 & 1.05 & 1.13 & $<0.001$ \\
\hline Intellectual and developmental disability & & & & & 0.53 & 0.49 & 0.56 & $<0.001$ \\
\hline Dementia & & & & & 0.55 & 0.49 & 0.62 & $<0.001$ \\
\hline Vocal and speech impairment & & & & & 0.90 & 0.89 & 0.92 & $<0.001$ \\
\hline Motion and balance impairment & & & & & 0.95 & 0.78 & 1.16 & 0.636 \\
\hline Facial disfigurements & & & & & 1.17 & 0.92 & 1.50 & 0.208 \\
\hline Intractable epilepsy & & & & & 1.53 & 1.18 & 1.98 & 0.001 \\
\hline Rare diseases & & & & & 0.76 & 0.42 & 1.35 & 0.347 \\
\hline Autism & & & & & 0.85 & 0.42 & 1.73 & 0.653 \\
\hline Other $^{\mathrm{b}}$ & & & & & 1.45 & 0.64 & 3.32 & 0.376 \\
\hline
\end{tabular}

a. Both Model A and Model B controlled for seven control variables, namely, sex, age, monthly salary, urbanization level of the residential area, comorbidity severity, dental calculus cleaning, and free adult health examination; b. Others: chromosomal abnormalities, inborn errors of metabolism, and congenital defects. 
in that meta-analysis, factors such as heterogeneity and a small sample size [4] may have led to biased results. One of the analysed studies mentioned that some rural residents were not included, and the data collection time was brief, which might have led to overestimation of the study results, causing the probability of CRC screening in people with disability to be the same as that in people without disability [5]. To maximize the accuracy of the study results, following previous studies [27, 28], in addition to using nationwide data, this study adopted two steps (PSM and control variables) to better control for other relevant factors. In studies of other cancer screenings, health inequality in people with disability is common. A systematic retrospective study showed that the utilization rate of cancer screening in people with disability was significantly lower than that in people without disability [6], and some research on other cancers in Taiwan has also led to similar conclusions [10-13].

This study found that inequality existed not only between people with disability and the general population but also among people with different types of disability. Among people with disability who are eligible for free CRC screening, the probability of receiving CRC screening in people in the four categories of disability (intellectual and developmental disability, dementia, multiple disabilities, and moving functional limitation; $\mathrm{OR}=0.53$, $0.55,0.62$ and 0.81 , respectively) was significantly lower than that in the general population. In contrast, the probability of receiving CRC screening in four other categories of disability (chronic mental health conditions, visual impairment, and intractable epilepsy; $\mathrm{OR}=1.04$, 1.09 , and 1.53, respectively) was significantly higher than that in the general population. Inequality among different categories of disability was also found in a CRC screening study in the United States [29]. This empirical study found that health inequality in Taiwan is consistent with the WHO statement that the health status of people with disability is much lower than that of people without disability around the world [1]. The WHO report also indicated that the health inequality phenomenon can be overcome [2]. To help people with disability overcome certain obstacles [30, 31], Taiwan has introduced a variety of measures to increase the accessibility of medical care for people with disability, such as special outpatient clinics, accessible hospitals, home care, transportation subsidies, and assistive device subsidies [3, 32]. Regarding the relevant factor of residence area, the OR of receiving CRC screening in areas with low urbanization (level 3-6) $(\mathrm{OR}>1)$ was significantly higher than that in areas with the highest urbanization $(\mathrm{OR}=1)$. The results of this study support the fact that Taiwan has promoted many programmes to effectively eliminate geographical barriers and thereby improve the accessibility of health services, i.e., regular fixed medical care and regular mobile medical care provided by physicians, in remote areas. Since 1999, the integrated delivery system (IDS) policy has been promoted. Under Taiwan's NHI system, major hospitals in urban areas are responsible for the delivery of medical care and preventive health care services in specific remote towns and villages [33]. A study on cervical cancer screening in Taiwan also obtained similar results [12]. In short, in accordance with the recommendations of the WHO [1], Taiwan has been working hard on legal, policy, institutional, and environmental ways to eliminate health inequalities between people with and without disability [3]. However, continuous improvements are still needed so that the health condition of Taiwanese people with disability can be further improved.

Because the data in this study were from secondary sources, information such as self-consciousness, knowledge, attitudes, and family history could not be obtained. People with better knowledge and attitudes or with a family disease history may be more likely to undergo CRC screening. Our study results showed differences in the uptake of CRC screening with FIT between people with and without disability, and these differences might result from people with different knowledge, attitudes, and family disease histories. In the future, we can conduct a survey study to examine the above-mentioned variables associated with the uptake of CRC screening with FIT in disabled people.

\section{Conclusions}

Among people meeting the CRC screening criteria in Taiwan, people with disability were less likely to undergo CRC screening than people without disability. This health inequality in Taiwan is consistent with the WHO statement that the health status of people with disability is much lower than that of people without disability around the world, suggesting that continuous efforts should be made to eliminate health inequality between people with and without disability.

\section{Abbreviations \\ CRC: Colorectal cancer; FIT: Faecal immunochemical testing; NHI: National health insurance; NHIRD: National health insurance research database; NCCN: National comprehensive cancer network; PVS: Persistent vegetative state; CCl: Charlson comorbidity index; PSM: propensity score matching; NT\$: New Taiwan dollar; OR: Odds ratio}

\section{Acknowledgements}

We are grateful for the use of the National Health Insurance Research Database and the Disability Registration Database provided by the Statistics Centre of the Ministry of Health and Welfare, Taiwan. We are also grateful to the Health Data Science Center, China Medical University Hospital, for providing administrative, technical, and funding support.

\section{Authors' contributions}

Conception and design were conducted by CML, WHH, WCT, and PTK; collection and assembly of data were performed by WHH, WCT, PTK, and 
LTC; data analysis and interpretation were conducted by CML, PTK, LTC, and WCT; manuscript writing was carried out by CML, WHH, WCT, and LTC; final approval of the manuscript was given by all authors.

\section{Funding}

This study was supported by grants (MOST105-2410-H-468-017; CMU109-S08) from the Ministry of Science and Technology and China Medical University, Taiwan.

\section{Availability of data and materials}

Regarding the data availability, data were obtained from the National Health Insurance Research Database published by the Ministry of Health and Welfare, Taiwan. Due to legal restrictions imposed by the Taiwanese government related to the Personal Information Protection Act, the database cannot be made publicly available. All researchers can apply to use the databases to conduct their studies. Requests for data can be sent as a formal proposal to the Health and Welfare Data Science Center of the Ministry of Health and Welfare, Taiwan (http://www.mohw.gov.tw/EN/Ministry/Index. aspx). Any raw data are not allowed to be removed from the Health and Welfare Data Science Center. The restrictions prohibited the authors from making the minimal data set publicly available.

\section{Declarations}

\section{Ethics approval and consent to participate}

This study used secondary databases managed and released by the government for academic research. Patient identifications in the National Health Insurance Research Database and the Disability Registration Database were scrambled. All patients without identifications for academic research use and personal privacy were protected in this study. This study did not involve human participants. The study guidelines followed for this study were in accordance with the Declaration of Helsinki. The Research Ethics Committee of Dali JEN-AI Hospital gave approval for informed consent waiver in this study and approved this study (IRB No: 105-14).

\section{Consent for publication}

Not applicable.

\section{Competing interests}

The authors have no conflicts of interest to declare.

\begin{abstract}
Author details
${ }^{1}$ Department of Public Health, China Medical University, Taichung, Taiwan. ${ }^{2}$ Genetic and Rare Disease Center, China Medical University Hospital, Taichung, Taiwan. ${ }^{3}$ Department of Gastroenterology and Hepatology, Yee Zen General Hospital, Taoyuan City, Taiwan. ${ }^{4}$ Department of Healthcare Administration, Asia University, Taichung, Taiwan. ${ }^{5}$ Department of Medical Research, China Medical University Hospital, China Medical University, Taichung, Taiwan. ${ }^{6}$ Department of Health Services Administration, China Medical University, No. 100, Sec. 1, Jingmao Road, Beitun District, Taichung 406040, Taiwan.
\end{abstract}

\section{Received: 18 November 2020 Accepted: 19 May 2021}

Published online: 02 June 2021

\section{References}

1. WHO. World report on disability 2011. Geneva: WHO Library Cataloguing-inPublication Data; 2011.

2. WHO. 10 facts on disability. 2017. https://www.who.int/features/factfiles/disa bility/en/. Accessed 22 Oct 2020.

3. Chiou ST. 2015 annual report of health promotion administration. Taipei: Health Promotion Administration Ministry of Health and Welfare; 2015.

4. Byrnes K, Hamilton S, McGeechan GJ, O'Malley C, Mankelow J, Giles EL. Attitudes and perceptions of people with a learning disability, family carers, and paid care workers towards cancer screening programmes in the United Kingdom: a qualitative systematic review and meta-aggregation. PsychoOncol. 2020;29(3):475-84. https://doi.org/10.1002/pon.5311.

5. lezzoni LI, Kurtz SG, Rao SR. Trends in colorectal cancer screening over time for persons with and without chronic disability. Disabil Health J. 2016;9(3): 498-509. https://doi.org/10.1016/j.dhjo.2016.02.003.
6. Edwards DJ, Sakellariou D, Anstey S. Barriers to, and facilitators of, access to cancer services and experiences of cancer care for adults with a physical disability: a mixed methods systematic review. Disabil Health J. 2020;13(1): 100844. https://doi.org/10.1016/j.dhjo.2019.100844.

7. Kung PT, Tsai WC, Li YH. Determining factors for utilization of preventive health services among adults with disabilities in Taiwan. Res Dev Disabil. 2012;33(1):205-13. https://doi.org/10.1016/j.ridd.2011.09.006.

8. Yen SM, Kung PT, Tsai WC. Factors associated with free adult preventive health care utilization among physically disabled people in Taiwan: nationwide population-based study. BMC Health Serv Res. 2014;14(1):610. https://doi.org/10.1186/s12913-014-0610-5.

9. Yen SM, Kung PT, Chiu LT, Tsai WC. Related factors and use of free preventive health services among adults with intellectual disabilities in Taiwan. BMC Health Serv Res. 2014;14(1):248. https://doi.org/10.1186/14726963-14-248.

10. Chen LS, Chou YJ, Tsay JH, Lee CH, Chou P, Huang N. Variation in the cervical cancer screening compliance among women with disability. J Med Screen. 2009;16(2):85-90. https://doi.org/10.1258/jms.2 009.008061.

11. Yen SM, Kung PT, Tsai WC. The characteristics and relevant factors of pap smear test use for women with intellectual disabilities in Taiwan. BMC Health Serv Res. 2014;14(1):240. https://doi.org/10.1186/1472-6963-14-240.

12. Huang $\mathrm{KH}$, Tsai WC, Kung PT. The use of pap smear and its influencing factors among women with disabilities in Taiwan. Res Dev Disabil. 2012; 33(2):307-14. https://doi.org/10.1016/j.ridd.2011.09.016.

13. Yen SM, Kung PT, Tsai WC. Mammography usage with relevant factors among women with mental disabilities in Taiwan: a nationwide populationbased study. Res Dev Disabil. 2015;37:182-8. https://doi.org/10.1016/j.ridd.2 014.10.052.

14. Levin TR, Corley DA, Jensen CD, Schottinger JE, Quinn VP, Zauber AG, et al. Effects of organized colorectal cancer screening on cancer incidence and mortality in a large community-based population. Gastroenterology. 2018; 155:1383-91.e5.

15. US Preventive Services Task Force. Screening for colorectal cancer: U.S. preventive services task force recommendation statement. Ann Intern Med. 2008;149:627-37.

16. Benson VS, Atkin WS, Green J, Nadel MR, Patnick J, Smith RA, et al. Toward standardizing and reporting colorectal cancer screening indicators on an international level: the international colorectal cancer screening network. Int J Cancer. 2012;130(12):2961-73. https://doi.org/10.1002/ijc.26310.

17. Su SY, Huang JY. Effect of nationwide screening program on colorectal cancer mortality in Taiwan: a controlled interrupted time series analysis. Int J Color Dis. 2020;35(2):239-47. https://doi.org/10.1007/s00384-019-03468-y.

18. Wang YW, Chen HH, Wu MS, Chiu HM. Current status and future challenge of population-based organized colorectal cancer screening: lesson from the first decade of Taiwanese program. J Formos Med Assoc. 2018;117(5):35864. https://doi.org/10.1016/j.jfma.2017.09.010.

19. Lee YC, Hsu CY, Chen SL, Yen AM, Chiu SY, Fann JC, et al. Effects of screening and universal healthcare on long-term colorectal cancer mortality. Int J Epidemiol. 2019;48(2):538-48. https://doi.org/10.1093/ije/dyy182.

20. Lee YH, Kung PT, Wang YH, Kuo WY, Kao SL, Tsai WC. Effect of length of time from diagnosis to treatment on colorectal cancer survival: a population-based study. PLoS One. 2019;14(1):e0210465. https://doi.org/1 0.1371/journal.pone.0210465.

21. Hsu YH, Kung PT, Wang ST, Fang CY, Tsai WC. Improved patient survivals with colorectal cancer under multidisciplinary team care: a nationwide cohort study of 25,766 patients in Taiwan. Health Policy. 2016;120(6):674-81. https://doi.org/10.1016/j.healthpol.2016.04.001.

22. Mackay C, Ramsay G, Rafferty A, Loudon M. Impact of the scottish bowel cancer screening programme on patient and tumour characteristics at a single Centre. J Eval Clin Pract. 2014;20(1):7-11. https://doi.org/10.1111/ jep.12071.

23. Taiwan's NHI. The national health insurance statistics, 2014. 2014. https:// www.nhi.gov.tw/English/Content_List.aspx?n=8162ED7256773F45\&topn=61 6B97F8DF2C3614. Accessed 22 Oct 2020.

24. Huang SK. 2013-2014 national health insurance annual report. Taipei, Taiwan: National Health Insurance Administration, Ministry of Health; 2013.

25. Liu CY, Hung YT, Chuang YL, Chen YJ, Weng WS, Liu JS, et al. Incorporating development stratification of Taiwan townships into sampling design of large scale health interview survey. J Health Manag. 2006;4:1-22. 
26. Deyo RA, Cherkin DC, Ciol MA. Adapting a clinical comorbidity index for use with ICD-9-CM administrative databases. J Clin Epidemiol. 1992;45(6):613-9. https://doi.org/10.1016/0895-4356(92)90133-8.

27. Rosenbaum PR, Rubin DB. The central role of the propensity score in observational studies for causal effects. Biometrika. 1983;70(1):41-55. https:// doi.org/10.1093/biomet/70.1.41.

28. Pillay B, Wootten AC, Crowe H, Corcoran N, Tran B, Bowden P, et al. The impact of multidisciplinary team meetings on patient assessment, management and outcomes in oncology settings: a systematic review of the literature. Cancer Treat Rev. 2016;42:56-72. https://doi.org/10.1016/j. ctrv.2015.11.007.

29. Deroche CB, McDermott SW, Mann JR, Hardin JW. Colorectal cancer screening adherence in selected disabilities over 10 years. Am J Prev Med. 2017:52(6):735-41. https://doi.org/10.1016/j.amepre.2017.01.005.

30. Beange $H$, McElduff A, Baker W. Medical disorders of adults with mental retardation: a population study. Am J Ment Retard. 1995;99(6):595-604.

31. Lennox NG, Diggens JN, Ugoni AM. The general practice care of people with intellectual disability: barriers and solutions. J Intellect Disabil Res. 1997; 41(Pt 5):380-90. https://doi.org/10.1111/j.1365-2788.1997.tb00725.x.

32. Lin JD, Lee PN, Yen CF, Wu J. The health status profile of persons with intellectual disability in institutions in Taiwan. J Med Sci (Taiwan). 2003;23: 285-90.

33. Chan WSH. Taiwan's healthcare report 2010. EPMA J. 2010;1(4):563-85. https://doi.org/10.1007/s13167-010-0056-8.

\section{Publisher's Note}

Springer Nature remains neutral with regard to jurisdictional claims in published maps and institutional affiliations.

Ready to submit your research? Choose BMC and benefit from:

- fast, convenient online submission

- thorough peer review by experienced researchers in your field

- rapid publication on acceptance

- support for research data, including large and complex data types

- gold Open Access which fosters wider collaboration and increased citations

- maximum visibility for your research: over $100 \mathrm{M}$ website views per year

At $\mathrm{BMC}$, research is always in progress.

Learn more biomedcentral.com/submissions 